\title{
Políticas para a inovação no Brasil: efeitos sobre os setores de energia elétrica e de bens de informática*
}

\author{
Henrique M. Barros** \\ Danny P. Claro*** \\ Fabio R. Chaddad****
}

SumÁrio: 1. Introdução; 2. Revisão da literatura; 3. Metodologia; 4. O caso do setor de bens de informática no polo industrial de Manaus; 5 . O caso do setor de energia elétrica no Brasil; 6. Discussões e conclusões.

Summary: 1 . Introduction; 2 . Literature review; 3 . Methodology; 4 . The case of the IT goods sector in the industrial pole of Manaus; 5 . The case of the electric power sector in Brazil; 6. Discussion and conclusion.

Palavras-chave: inovação; aprendizagem tecnológica; políticas públicas.

KEY WORDs: innovation; technological learning; public policies.

Este artigo examina como políticas públicas afetam o comportamento das empresas com relação à inovação. Através do método de pesquisa de estudos de caso, o trabalho identifica como as empresas, em dois setores industriais no Brasil, têm respondido aos esforços governamentais para estimular sua capacitação tecnológica. São comparadas empresas do setor de energia elétrica do Brasil e do setor de informática do

* Artigo recebido em maio 2008 e aceito em jul. 2009.

** Doutor em administração de empresas pela University of Warwick, Inglaterra. Professor e coordenador do mestrado profissional em administração do Instituto de Ensino e Pesquisa (Insper). (O processo de homologação da marca Insper — Instituto de Ensino e Pesquisa — segue os trâmites legais no Ministério da Educação.) Endereço: Rua Quatá, 300 - Vila Olímpia - CEP 04546-042, São Paulo, SP, Brasil. E-mail: henriquemb@insper.org.br>.

$* * *$ Doutor em administração de empresas pela Wageningen University, Holanda. Professor e coordenador do Centro de Pesquisas em Estratégia do Instituto de Ensino e Pesquisa (Insper). Endereço: Rua Quatá, 300 - Vila Olímpia - CEP 04546-042, São Paulo, SP, Brasil. E-mail: dannypc@insper.org.br.

$* * * *$ Doutor em economia agrícola pela University of Missouri, EUA. Professor da University of Missouri e professor visitante do Instituto de Ensino e Pesquisa (Insper). Endereço: Department of Agricultural Economics, University of Missouri, 125B - Mumford Hall - Columbia - MO 65211, EUA. E-mail: chaddadf@missouri.edu. 
polo industrial de Manaus. De forma geral, os resultados indicam que as políticas de inovação têm contribuído para aumentar o interesse das empresas por inovação. No entanto, esse interesse tem se mostrado maior por parte das empresas cujo controle de capital é estatal e/ou estrangeiro, do que pelas empresas de controle de capital privado nacional. Isso é particularmente relevante, pois as empresas de capital privado nacional atuam em mercados pouco regulamentados, em que o nível de competição é crescente. O limitado interesse dessas empresas por inovação reforça a ideia de que políticas de inovação não podem englobar apenas ações voltadas para o lado da oferta, nem podem ser dissociadas de políticas voltadas para o fortalecimento do ambiente institucional.

Policies for innovation in Brazil: effects on the electric power sector and IT goods sector

This article examines how public policies to foster innovation affect companies' behavior. Based on the case study research method, the article identifies how firms operating in the Brazilian electric power and IT sectors of the Manaus industrial district have responded to public efforts to stimulate technological innovation in both sectors. In general, the results suggest that these policies have increased private interest for innovation. However, this interest is greater among state controlled and multinational corporations than among domestic private companies. This finding is particularly relevant because domestic companies operate in deregulated markets with increasing competitive pressures. The limited interest of domestic companies for innovation suggests that innovation policies should not be limited to supply side factors and cannot be dissociated from policies aimed at strengthening the institutional environment.

\section{Introdução}

Este artigo examina como, no Brasil, políticas públicas voltadas à inovação têm afetado as empresas dos setores de bens de informática e de energia elétrica. O reconhecimento de que a tecnologia é um dos fatores que contribuem para o crescimento econômico tem motivado os países a incorporarem aquela variável em suas políticas públicas. Apesar de tal incorporação ser mais frequentemente observada em países de economias mais avançadas, ela também já pode ser vista em países de industrialização tardia. Na América Latina, por exemplo, apesar desses países terem buscado o desenvolvimento industrial através da adoção de uma política de substituição de importação dissociada de desenvolvimento tecnológico (Teixeira, 2005), esse panorama parece estar se modificando, dado que a limitada competitividade desses países na arena internacional é, em parte, atribuída à falta de um ambiente interno favorável à inovação (Katz, 2004). 
No Brasil pode-se observar, em determinados setores, um modelo pautado na indução de investimentos em pesquisa \& desenvolvimento (P\&D) através de políticas públicas que determinam valores mínimos para tais investimentos. Todavia, pouco se sabe sobre os reais efeitos de tais políticas e é esse espaço que esta pesquisa visa preencher. Dado o caráter exploratório do problema, adotou-se uma abordagem qualitativa para sua compreensão. A investigação consiste em estudos de casos de dois setores industriais brasileiros que se enquadram na política pública mencionada supra. Mais especificamente, o estudo identifica como as empresas do setor de energia elétrica no Brasil e do setor de bens de informática do polo industrial de Manaus têm respondido aos esforços governamentais para promover a inovação.

Os resultados indicam que as políticas de inovação têm contribuído para aumentar o interesse das empresas por atividades de inovação. No entanto, esse interesse tem se mostrado maior por parte das empresas cujo controle de capital é estatal ou estrangeiro, do que por parte das empresas de controle de capital privado nacional. Isso é particularmente relevante, na medida em que as empresas de capital privado nacional, muitas vezes, atuam em mercados pouco regulamentados e com crescente competição. Portanto, apesar de estarem sujeitas às forças de mercado, o limitado interesse das empresas de capital privado nacional por atividades relacionadas à inovação reforça a ideia de que políticas de inovação não podem englobar apenas ações voltadas para o lado da oferta, nem podem ser dissociadas de políticas voltadas para o fortalecimento do ambiente institucional.

A próxima seção apresenta a revisão da literatura com o propósito de contextualizar o evento investigado. A terceira seção reporta o método de pesquisa empregado. A quarta seção e a quinta seção descrevem os resultados encontrados a partir da pesquisa de campo. A sexta seção faz uma análise comparativa dos resultados e conclui o trabalho.

\section{Revisão da literatura}

Há anos a literatura econômica (Schumpeter, 1942; Young, 1928) já tinha argumentado a respeito da relevância da variável tecnológica para o crescimento econômico. No entanto, sua formalização em modelos de crescimento econômico foi gradual, tendo se iniciado em meados do século passado (Solow, 1957) e se sofisticado a partir da década de 1980 (Romer, 1986 e 1990). Mais recentemente, muitos debates se iniciaram com o propósito de discutir e 
entender como o Estado deveria (ou não) intervir no desenvolvimento do seu parque industrial através de políticas de inovação (Teixeira, 2005).

A crescente preocupação com políticas públicas de inovação decorre do seu caráter multidisciplinar. Isso significa que a necessidade de atender a vários interesses não está, necessariamente, condicionada à existência de um arcabouço ótimo, em que políticas públicas possam ser analisadas. Dessa forma, mesmo que algumas disciplinas especializadas, como a economia, possam contribuir para essa análise, sua contribuição é apenas parcial (Metcalfe, 1995). Isso, entretanto, não diminui sua relevância para a formulação e análise de políticas públicas, mas contribui para que tais ações sejam guiadas por outras questões paralelas à agenda pautada na teoria econômica (Nelson e Winter, 1982).

No caso da América Latina, por exemplo, a influência da Comissão Econômica para a América Latina (Cepal) foi fundamental na adoção da estratégia de substituição de importação (Teixeira, 2005). Além disso, a não observância de alguns elementos durante o processo de formulação de políticas públicas talvez não seja surpreendente sob a perspectiva de racionalidade limitada dos tomadores de decisão; perspectiva que serviu para Nelson e Winter (1977) refutarem a maximização como regra de decisão num contexto de inovação. Segundo os autores, em condições de incerteza, que são típicas de ambientes de inovação, os agentes recorrem a heurísticas para balizar suas decisões. Portanto, as heurísticas das firmas juntamente com as características da tecnologia e dos mercados não permitem a existência de um padrão único de geração e difusão de inovações. Para os autores, portanto, o foco da política industrial deve ser no desenvolvimento de mecanismos que favoreçam a interação entre os vários agentes. Essa perspectiva passou a ser discutida na literatura econômica sob a rubrica da "economia evolucionista" (ou evolucionária) e através dessa discussão surgiu o conceito de "sistema nacional de inovação" (Freeman, 1995).

A abordagem do "sistema nacional de inovação" tem como elemento central o processo de aprendizagem pelos agentes envolvidos. Como consequência, uma das contribuições dessa abordagem tem sido a mudança, no âmbito de políticas públicas, da concepção do processo de inovação de um modelo linear para um modelo interativo (Lundvall, 2005). Mais especificamente, o processo de inovação é constituído de interações entre os agentes envolvidos e que a função pesquisa \& desenvolvimento (P\&D) não deve ser tratada isoladamente.

Essa abordagem sugere que políticas governamentais para a inovação não devem se concentrar apenas no volume de investimento e nas áreas da 
tecnologia que recebem investimentos, já que um sistema de inovação é, na verdade, um arranjo organizacional e institucional. Dessa forma, o desenho de políticas de inovação deve contemplar também a criação de um ambiente institucional favorável à inovação (Edquist e Johnson, 1997). Segundo Mowery (1995), políticas explícitas com o propósito de estimular a inovação podem não exercer uma influência tão grande no comportamento das firmas quanto outras políticas públicas (fiscal, macroeconômica, educacional). Sendo assim, subsidiar atividades de P\&D pode exercer apenas papel marginal se as outras partes relevantes para o processo de inovação não estão bem integradas (Metcalfe, 1995).

Devido aos seus elementos constituintes (conhecimento, aprendizagem, interação), a abordagem sistêmica tem sido utilizada para se investigar como o processo de inovação se dá em outras dimensões (setor industrial, região) ou como essas várias dimensões afetam o processo de inovação. O estudo de como a dimensão geográfica interfere na inovação parece ter se tornado particularmente de interesse ao longo das últimas décadas (Asheim e Coenen, 2004). Os trabalhos de Porter (1990), sobre como características regionais afetam o êxito das empresas, e de Saxenian (1994), sobre o sistema industrial do Vale do Silício, são exemplos desse esforço para compreender a relação entre a dimensão regional e o processo de inovação. O que caracteriza um sistema regional de inovação é a interação sistemática entre as empresas e as demais organizações. No entanto, a interação social, a confiança e as instituições se fazem necessárias. Além disso, para que as interações possam levar ao sucesso dos projetos, são necessárias redes locais e remotas de cooperação (Cooke, 2001).

Em linhas gerais, a aglomeração territorial tende a promover a inovação desde que seus agentes estejam incorporados em uma rede de interações (Porter, 2000). No entanto, em um contexto de economia emergente, pouco se sabe como as dimensões nacional e regional afetam o estímulo à inovação nas empresas. Cassiolato e Lastres (2000), por exemplo, observaram que no Mercosul as políticas de desregulamentação, privatização e liberalização afetaram diferentemente o esforço de inovação das empresas locais e estrangeiras durante os anos 1990. Segundo os autores, algumas empresas locais demonstraram comprometimento com a inovação, mas isso não significou um fortalecimento do sistema local de inovação. Primeiro, porque as empresas estrangeiras passaram a importar recursos ao invés de buscá-los localmente, inviabilizando vários canais de produção. Segundo, porque os novos entrantes não estavam interessados em participar de arranjos produtivos locais e logo não interagiam com o sistema doméstico de inovação. Por último, porque o 
maior comprometimento com a inovação ocorreu apenas por parte de algumas poucas empresas domésticas.

O comportamento das empresas multinacionais observado por Cassiolato e Lastres (2000) no Mercosul não seria inesperado, dado que o desenvolvimento de atividades tecnológicas fora do país de origem da firma obedece a um padrão evolucionário que pode ser interrompido se aquelas atividades não estiverem alinhadas com os objetivos da corporação (Ronstadt, 1984). Tendo em vista as limitadas competências tecnológicas da região, seria de se esperar que a abertura de mercado estimulasse a busca de alternativas em outros mercados. Conforme observado por Patel e Pavitt (1992), ainda que alguma atividade tecnológica fosse desenvolvida nos vários mercados onde a empresa atua, os principais centros de $\mathrm{P} \& \mathrm{D}$ eram tradicionalmente limitados ao próprio país de origem ou aos países da tríade (Estados Unidos, Japão e Europa Ocidental). A necessidade das empresas terem acesso às competências tecnológicas que lhes garantissem um maior nível de competitividade justificava esse comportamento (Dunning, 1994). Cantwell (1995), por exemplo, identificou que as empresas multinacionais buscavam localizar suas atividades de P\&D em regiões com vantagens comparativas. Além disso, as empresas estão se tornando mais sensíveis aos gastos com $\mathrm{P} \& \mathrm{D}$, procurando países com mão de obra barata para o desenvolvimento de atividades de geração de tecnologia (Gammeltoft, 2006). Todavia, o fator custo parece ser um determinante maior para atividades de desenvolvimento tecnológico do que de pesquisa (Von Zedwitz e Gassmann, 2002).

No Brasil, Ariffin e Figueiredo (2003) observaram a formação de competências tecnológicas nas subsidiárias de multinacionais na indústria eletrônica do polo industrial de Manaus. No entanto, os autores não observaram se esse comportamento seria uma resposta às políticas governamentais para promover a inovação na região. Como o Brasil tem adotado, em determinados setores, um modelo pautado na indução de investimentos em pesquisa \& desenvolvimento (P\&D) através de políticas públicas que determinam valores mínimos para tais investimentos, é relevante entender a eficácia de tais políticas. Santos Jr. (2004), por exemplo, identificou recentemente que os investimentos em P\&D nas empresas do polo industrial de Manaus têm sido crescentes em resposta às políticas governamentais. Tendo em vista os resultados de Ariffin e Figueiredo (2003) sobre a evolução da formação de competências tecnológicas nas subsidiárias de multinacionais instaladas na região, os achados de Santos Jr. (2004) poderiam estar refletindo apenas o comportamento das multinacionais. E se isso, de fato, estiver acontecendo, a questão que se apresenta é se tal fenômeno estaria ocorrendo em virtude de especificidades regionais ou se seria um fenômeno presente na dimensão nacional também. 
Este trabalho, portanto, identifica como as empresas respondem aos esforços governamentais para promover a inovação tecnológica e se existem diferenças nos efeitos de acordo com o escopo geográfico (i.e., regional ou nacional) e com as especificidades de tais políticas. O método de pesquisa empregado é detalhado na próxima seção.

\section{Metodologia}

Partindo do objetivo de investigar um fenômeno contemporâneo em um contexto real e em decorrência da impossibilidade de controle sobre os eventos comportamentais por parte dos pesquisadores, optou-se pelo estudo de caso (Yin, 1994). Com vistas à percepção da totalidade de uma situação, selecionaram-se dois casos que apresentam pelo menos uma característica marcante em relação ao tópico pesquisado (Bruyne, Herman e Schotheete, 1982). Essa característica marcante diz respeito à existência de ações governamentais concretas para estimular a inovação. Além disso, ambos os casos apresentam semelhanças quanto à forma como a política de inovação possibilita às empresas investirem em P\&D.

Todavia, dado o enfoque da pesquisa, buscou-se também uma comparabilidade decorrente de algumas diferenças entre as empresas. Por exemplo: como o objetivo é comparar os efeitos da política de inovação em níveis regional e nacional foram utilizados dois grupos de empresas: 1 . um grupo cujas atividades de inovação podem ser afetadas por políticas regionais de inovação (i.e., setor eletroeletrônico do polo industrial de Manaus - PIM); e 2. outro grupo cujas atividades de inovação podem ser afetadas por políticas nacionais de inovação (i.e., setor de energia elétrica nacional). Por último, buscou-se comparar um setor em que os investimentos em P\&D são opcionais (i.e., setor eletroeletrônico do PIM) e outro em que tais investimentos são compulsórios (i.e., setor de energia elétrica nacional).

As evidências coletadas para a análise dos casos foram baseadas em variáveis qualitativas, uma vez que se pretendeu analisar como as políticas de incentivo à inovação têm afetado as empresas. Portanto, procurou-se explorar as vantagens do estudo de caso, uma vez que os componentes (conhecimento, aprendizagem, interação) dos sistemas de inovação em que as empresas estão inseridas (nacional e regional) envolvem agentes e suas relações sociais, estabelecidas em diversos ambientes de pesquisa (Godoy, 1995). A coleta dos dados foi realizada em três diferentes fontes: documentos, entrevistas e observações diretas.

Em ambos os setores estudados, os dados primários foram obtidos a partir das entrevistas "face a face". A média de duração das entrevistas foi cerca de uma 
hora e meia e elas foram conduzidas com o auxílio de um roteiro semiestruturado para manter o foco nos assuntos mais relevantes sem perder a flexibilidade que esse tipo de atividade demanda. As entrevistas foram realizadas com os encarregados dos programas de P\&D em cada organização, que ocupavam cargos de superintendência, gerência ou assessoria de diretoria. Para se ter uma visão mais sistêmica dos efeitos das políticas de inovação, as organizações abordadas para compor a nossa amostra incluem não somente empresas de bens de informática e de energia elétrica, mas também centros de inovação, ${ }^{1}$ universidades e órgãos governamentais relacionados às políticas de inovação. Entre os tópicos abordados estão os aspectos legais e suas consequências, as atividades e o comportamento dos agentes em relação à $\mathrm{P} \& \mathrm{D}$, e os entraves aos programas de $\mathrm{P} \& \mathrm{D}$.

No caso do setor de energia elétrica foram selecionadas sete empresas conforme listagem da Aneel, a qual também contribuiu com informações sobre a política de inovação para o setor. Além das empresas e da Aneel, dois centros de inovação e uma universidade forneceram informação sobre os efeitos da política de inovação no setor. No caso do setor de bens de informática do PIM, foram selecionadas seis empresas (quatro multinacionais e duas nacionais) fabricantes de bens de informática, conforme listagem apresentada pela Superintendência da Zona Franca de Manaus (Suframa). A Suframa também participou como informante para a pesquisa, assim como a Secretaria de Ciência e Tecnologia do estado e mais cinco centros de inovação e duas universidades. Os dados secundários foram obtidos por meios eletrônicos, através de sites de órgãos vinculados ao governo, material disponibilizado pelas empresas, além de veículos de notícias e canais de comunicação especializados.

Número de organizações que compõem a amostra

\begin{tabular}{|lcc|}
\hline Tipo & Bens de informática & Energia elétrica \\
\hline Empresas & 6 & 7 \\
Centros de inovação & 5 & 2 \\
Universidades & 2 & 1 \\
Órgãos governamentais & 2 & 1 \\
Total & 15 & 11 \\
\hline
\end{tabular}

\footnotetext{
${ }^{1}$ Instituições privadas de pesquisa e desenvolvimento.
} 


\section{0 caso do setor de bens de informática no polo industrial de Manaus}

\section{Incentivos à inovação}

O setor de bens de informática faz parte do complexo eletrônico, o qual compreende os fabricantes de bens eletrônicos de consumo (televisores, DVDs), equipamentos para telecomunicações e automação, e componentes eletrônicos. Hoje, o setor de eletroeletrônicos é responsável por cerca de $50 \%$ do faturamento total do polo industrial de Manaus, o qual foi de quase US\$ 26 bilhões em 2007 e envolveu aproximadamente 100 mil empregos diretos.

O desenvolvimento do setor de bens de informática na região da Amazônia Ocidental tem origem na criação do parque industrial de Manaus. Com o fim do ciclo da borracha, novas medidas foram tomadas para integrar a região à economia do país. Em 1951, um modelo econômico foi concebido para Manaus com o objetivo de desenvolver as atividades regionais de indústria e comércio, e intensificar a cooperação entre o Brasil e os demais países amazônicos. Em 1957, o projeto se transformou em lei, sendo criada uma área de livre-comércio de importação, que ficou conhecida como Zona Franca de Manaus. Como os incentivos se mostraram insuficientes para alavancar a economia local, as diretrizes da política nacional para a Amazônia foram modificadas e, em 1967, a Zona Franca de Manaus (ZFM) foi reformulada. A mudança dotou a região de incentivos fiscais, os quais vêm promovendo a transformação da economia local. Os incentivos, que, na época, estavam previstos para durar 30 anos, já têm previsão de se estender até 2023 (Garcia, 2004).

Em paralelo às modificações das políticas para a região de Manaus, o governo também buscava desenvolver a indústria de informática em nível nacional. Assim, foi implantada em 1977 uma reserva de mercado que culminou, em 1984, em um novo marco regulatório que ficou conhecido como "Lei de Informática". Em 1991, o governo federal lançou a Nova Política Industrial e de Comércio Exterior, que abriu o mercado brasileiro aos produtos estrangeiros. A política industrial consistia, essencialmente, na redução progressiva do imposto de importação. Toda a indústria nacional sofreu os efeitos da medida e não foi diferente na ZFM.

Para adequar o regime fiscal e de importações da ZFM à nova política industrial e de comércio exterior, houve uma reformulação da Lei de Informática com o propósito de aumentar a competitividade das empresas, já que o setor de informática era considerado estratégico. Com a visão de que sem investimentos em P\&D as empresas de bens de informática instaladas no país 
não seriam capazes de enfrentar a concorrência internacional, a legislação buscou induzir investimentos em P\&D através de incentivos fiscais, incluindo a isenção do imposto sobre produto industrializado (IPI) e a redução sobre o imposto de renda.

Para se beneficiarem dos benefícios fiscais, as empresas teriam que investir em atividades de P\&D no Brasil. A exigência legal é que sejam empregados, no mínimo, $5 \%$ do faturamento decorrentes da comercialização de bens de informática no mercado doméstico (deduzidos os tributos correspondentes a tais comercializações, bem como o valor das aquisições de produtos incentivados pela lei). Do montante a ser destinado para P\&D ( $5 \%$ do faturamento), uma parte (no máximo 54\%) pode ser utilizada em atividades internas e outra parte (no mínimo 36\%) deve ser alocada para atividades externas, isto é, para atividades a serem realizadas através de convênios entre os fabricantes de bens de informática e outras organizações credenciadas no Ministério da Ciência e Tecnologia (e.g., universidades, centros de inovação). Ainda, dos recursos destinados para P\&D exigidos por lei, $10 \%$ devem ser destinados para o Fundo Nacional de Desenvolvimento Científico e Tecnológico (FNDCT).

Em âmbito nacional, a legislação determina que parte dos recursos destinados para atividades externas de P\&D deve ser alocada em determinadas regiões do país como forma de descentralizar a formação de competências em tecnologia da informação e promover o desenvolvimento regional. No entanto, para a região da Amazônia Ocidental, onde estão situados os estados do Amazonas, Acre, Rondônia e Roraima, a legislação tem uma redação ligeiramente diferente. As empresas situadas em outras partes do país não têm obrigação de investir em Manaus, embora nada as impeça de assim o fazer. Porém, os fabricantes de bens de informática situados na Amazônia Ocidental devem investir integralmente na própria região os $5 \%$ do faturamento que a lei especifica. Além disso, a empresa deve ter seu processo produtivo básico reconhecido pela Suframa, autarquia federal vinculada ao Ministério da Ciência e Tecnologia, e deve ser credenciada junto àquela instituição. Mais especificamente, junto ao Comitê de Pesquisa e Desenvolvimento da Amazônia (Capda), que foi criado em 2002 para coordenar as atividades de inovação incentivadas pela legislação.

\section{Impactos da política de inovação}

As informações levantadas durante as entrevistas convergiram para um impacto positivo das políticas públicas sobre as atividades de inovação tecnológica 
no polo industrial de Manaus (PIM). Anteriormente, ciência e tecnologia não estavam na pauta das atividades das empresas locais. A inexistência de uma política de inovação para a região fazia com que esta se caracterizasse por ser um grande parque fabril sem perspectiva de existência no longo prazo. Sem exceção, os entrevistados concordaram que a mudança no perfil tecnológico da região foi notável. Atualmente, as atividades de inovação tecnológica já criam uma possibilidade, ainda que frágil, de autossustentabilidade da indústria local.

Devido às particularidades do modelo econômico regional, que possui interfaces com outras políticas e ações governamentais, tais como incentivos fiscais em nível estadual, e a própria falta de experiência das empresas para lidar com a nova legislação, a gestão do processo de inovação foi difícil tanto para as empresas quanto para o governo. Com a criação, na Suframa, da Coordenação Geral de Gestão Tecnológica (CGTEC), que visa dar suporte às empresas no seu enquadramento à legislação, o panorama vem sendo modificado. Além disso, a atuação do poder público não está limitada à esfera federal. O governo estadual criou a Secretaria de Ciência e Tecnologia do Amazonas (SECT) e também a Fapeam (Fundação de Amparo à Pesquisa do Estado do Amazonas) em 2002, além de estar alocando mais recursos para a Universidade Estadual do Amazonas (UEA). Conforme apontado por Santos Jr. (2004), um dos resultados da política de inovação da região são os crescentes dispêndios em P\&D. Dados obtidos através da Suframa confirmam esse comportamento e, mais especificamente, demonstram que a maior parte dos investimentos é alocada externamente às empresas, ultrapassando $\mathrm{R} \$ 200 \mathrm{mi}$ lhões em 2004.

Como as empresas do PIM devem investir em P\&D na Amazônia Ocidental e uma parte dos investimentos tem que ser destinada para atividades externas, criou-se uma oportunidade para o surgimento de organizações privadas de P\&D. Sendo assim, outro resultado da política de inovação foi o surgimento de centros de inovação locais. No entanto, de acordo com alguns entrevistados, o surgimento de recursos disponibilizados pela legislação fez com que aparecessem várias organizações almejando se beneficiar inapropriadamente destes. Isso se modificou à medida que a Suframa passou a coordenar os recursos existentes e a orientar as empresas sobre a forma como os recursos deveriam ser empregados. A criação pela Suframa do Comitê de Pesquisa e Desenvolvimento da Amazônia (Capda) tem auxiliado na formulação e implementação da política regional de inovação. Um dos resultados imediatos do último esforço tem sido um melhor direcionamento dos recursos captados através do credenciamento de organizações que estão, de fato, habilitadas a recebê-los. 
Em alguns casos, o surgimento dos centros de inovação foi resultado do esforço das próprias empresas instaladas na região através de spin-offs de suas atividades de P\&D. Elas identificaram nessa ação uma forma de alocarem seus recursos e manterem estreito contato com os centros de inovação. Embora ainda recente, a atuação dos centros de inovação situados no PIM não está restrita a Manaus. Já existem centros de inovação prestando serviços para empresas de outras partes do país e até mesmo para os laboratórios centrais de P\&D de empresas multinacionais (MNEs), cujas subsidiárias estão instaladas em Manaus.

$\mathrm{O}$ trabalho de campo permitiu detectar que a origem de um daqueles centros de inovação está em outra região do país. Essa inserção pode sinalizar um potencial do mercado regional para atividades ligadas à geração de conhecimento. Todavia, os entrevistados informaram que o número de centros de inovação em Manaus parece ser suficiente para atender a demanda. Caso a demanda aumente, a percepção dos centros de inovação locais é que isso poderá fortalecê-los, já que serão necessários investimentos das empresas instaladas na região para reforçar as competências desses centros, tais como investimentos em equipamentos e no aumento do quadro de funcionários. Mais do que isso, a tendência é que as empresas busquem fortalecer os centros cuja origem está na própria região. De acordo com as entrevistas, o centro de inovação, cuja origem não está em Manaus, tem dificuldade para replicar seu modelo de negócio em outras regiões, tendo dificuldade ainda para alinhar a nova operação com a visão da organização de origem e replicar o desempenho que, até então, a caracterizou.

As universidades, especialmente as públicas, também têm sentido o impacto da política de inovação para a região. Elas criaram suas fundações para que pudessem estabelecer parcerias com as empresas. Ainda no âmbito acadêmico, os entrevistados também apontaram para o crescimento de organizações privadas de ensino superior e para a migração desse tipo de organização de outras partes do país para Manaus. Entretanto, de acordo com os entrevistados, as instituições privadas têm atuado mais na área de ensino, especialmente na graduação, do que na de pesquisa. Os entrevistados relataram que uma mudança no perfil da mão de obra local já ocorreu. O surgimento de centros de inovação habilitados a receber recursos determinados pela legislação também tem contribuído para essa mudança, pois passaram a demandar mão de obra especializada em atividades de pesquisa que praticamente inexistia na região.

De acordo com as entrevistas, as inovações em Manaus têm sido, em grande parte, induzidas pela Lei de Informática e o conteúdo tecnológico das atividades de P\&D parece estar mudando gradualmente. No início da década de 1990 os recursos alocados para inovação se concentravam em atividades de 
desenvolvimento tecnológico, caracterizadas por resultados obtidos num prazo relativamente curto e por apresentarem um conteúdo tecnológico pouco sofisticado. De acordo com alguns entrevistados, o foco das atividades era a criação de centrais de processamento de dados; até mesmo pela necessidade das empresas se tornarem mais competitivas num curto prazo. Os entrevistados relataram que, atualmente, as inovações desenvolvidas no PIM variam em termos de sofisticação. Embora já seja possível detectar atividades de pesquisa sendo realizadas nas empresas locais, elas ainda são esporádicas. Apesar de existirem exceções, o horizonte dos projetos não é de longo prazo, nem o conteúdo tecnológico das inovações é altamente sofisticado. No entanto, os entrevistados alegaram que é inegável a evolução tecnológica da indústria local. De fato, alguns eventos parecem corroborar essa percepção como, por exemplo, a premiação pela Financiadora de Estudos e Projetos (Finep) de centros de inovação (i.e., organizações privadas sem fins lucrativos que realizam P\&D) localizados em Manaus.

De forma geral, os entrevistados ressaltaram que o maior impacto da política de inovação para Manaus talvez não seja tanto o volume de recursos destinado para $\mathrm{P} \& \mathrm{D}$, mas sim a internalização de uma sistemática para gerir a inovação. Isso tem levado ao desenvolvimento de uma cultura voltada para atividades de inovação e, consequentemente, ao aprendizado do processo de inovação tecnológica. Todavia, segundo as entrevistas, os efeitos da política de inovação regional sobre as empresas não têm sido homogêneos. De acordo com os vários agentes entrevistados, as subsidiárias das multinacionais têm demonstrado um maior interesse em se engajar em atividades de inovação do que as empresas de capital privado nacional. No caso destas, as empresas da amostra com tal atributo argumentaram que os retornos da inovação são pequenos em face dos riscos de se inovar. Além disso, essas empresas relataram possuir limitada capacidade para investir em P\&D e seus mercados para explorar os resultados do esforço inovador não são grandes o suficiente para assegurar o retorno desejado. Apesar de a nossa amostra compor apenas duas empresas fabricantes de bens de informática com controle de capital privado nacional, tais justificativas também foram apresentadas pelos outros informantes, especialmente pelos centros de inovação, para comparar o nível de envolvimento das empresas situadas no PIM com a inovação.

\section{Entraves à inovação}

Apesar do interesse dos órgãos governamentais no desenvolvimento regional e dos esforços para se alavancar o PIM, as entrevistas revelaram várias barrei- 
ras à consolidação de um ambiente propício à inovação. Os entrevistados relataram que, no início da política de inovação, as empresas percebiam que os recursos alocados para P\&D eram impostos para que elas pudessem usufruir dos benefícios fiscais. No entanto, com o decorrer do tempo, algumas empresas já perceberam que as atividades de inovação tecnológica desenvolvidas na região estão permitindo que elas se tornem mais competitivas. Ainda assim pode-se dizer que o interesse das empresas em inovação é pequeno. A maioria delas, principalmente as menores, entende as atividades de P\&D como um custo irrecuperável, cujo retorno não compensa o esforço necessário para sua implementação e acompanhamento. Além disso, de acordo com os informantes dos centros de inovação, essas empresas apresentam grande resistência para participarem de atividades de P\&D porque isso implica no aumento da carga de trabalho já existente e por entenderem que não existe mercado no Brasil para os resultados desse tipo de atividade.

Os entrevistados concordaram que a disponibilidade de mão de obra com competências em P\&D é escassa na região, sendo frequentemente necessário buscar tais recursos em outras partes do país. Como resultado, o custo e a rotatividade dessa mão de obra acabam sendo elevados. Somente três instituições de ensino oferecem cursos de pós-graduação relacionados à tecnologia da informação (TI), sendo que a maioria dos cursos de pós-graduação oferecidos é do tipo lato sensu. Até o momento de conclusão do trabalho de campo, nenhum curso de doutorado na área era oferecido.

A escassez de recursos humanos afeta negativamente os centros de inovação em desenvolvimento na região. Além disso, essa escassez é uma efetiva barreira à entrada para os centros de inovação de outras partes do país. Nesse caso, outro agravante apontado por alguns entrevistados reside na percepção do papel desempenhado por centros de P\&D cuja origem não está em Manaus. De forma geral, o trabalho de campo observou uma resistência, por parte de alguns agentes locais, à entrada de novos centros de inovação em Manaus. $\mathrm{O}$ argumento contrário a tal movimento é de que como os recursos estão sendo gerados localmente, deveriam ser para desenvolver as organizações locais. Sendo assim, a entrada de organizações de outras partes do país é interpretada como um comportamento oportunista de um agente sem comprometimento com o desenvolvimento regional.

Apesar do esforço governamental e do reconhecimento pelas empresas de que o resultado desse esforço tem sido positivo, o ambiente institucional ainda está em formação. Um exemplo frequentemente citado pelas organizações entrevistadas foi a morosidade do governo para avaliar se os projetos executados estão dentro dos objetivos da política de inovação para a região. 
$\mathrm{O}$ ambiente institucional, portanto, ainda não consegue dar maior respaldo às empresas locais e parece ainda não ter sido suficientemente convincente para que elas, especialmente as de capital privado nacional, percebam que a política vigente é uma oportunidade para se fortalecerem competitivamente.

\section{0 caso do setor de energia elétrica no Brasil}

\section{Incentivos à inovação}

O setor elétrico brasileiro pode ser definido como o conjunto das atividades de geração, transmissão e distribuição ou comercialização de eletricidade. Ele é predominantemente hidroelétrico, pois a composição da matriz energética do país compreende $84 \%$ de energia hidráulica (Carneiro, 2000). Os incentivos para promover a inovação no setor surgiram em 2000 (Lei no 9.991), através dos quais as concessionárias de energia elétrica deveriam passar a alocar um percentual da receita operacional líquida (ROL) em projetos de pesquisa \& desenvolvimento (P\&D). Em 2001, o país passou por uma severa crise energética. Após os problemas de oferta de energia elétrica em 2001, os percentuais de aplicação em P\&D foram ajustados da seguinte forma:

v geradoras - 1,00\% em P\&D;

v transmissoras - $1,00 \%$ em P\&D;

v distribuidoras — 0,75\% em P\&D e 0,25\% em programas de eficiência.

Uma parte dos recursos que devem ser destinados para P\&D é gerida diretamente pelas empresas através de suas carteiras supervisionadas pela Agência Nacional de Energia Elétrica ("P\&D Aneel"). Desse montante, uma parcela tem que ser alocada em organizações de P\&D nacionais (e.g., universidades, centros de inovação) reconhecidas pelo Ministério da Ciência e Tecnologia (MCT). Além disso, 30\% dos recursos destinados para P\&D devem ser alocados nas regiões Norte, Nordeste e Centro-Oeste. Outra parte dos recursos das empresas não é gerida por elas, pois é destinada ao Fundo Nacional de Desenvolvimento Científico e Tecnológico (FNDCT) e à Empresa de Pesquisa Energética (EPE). A EPE começou a ser projetada após a criação da Câmara de Comercialização de Energia Elétrica (CCEE), em 2004, que substituiu o MAE com a incumbência de promover leilões de compra e venda de energia elétrica. O propósito da EPE é realizar estudos para dar suporte ao planejamento para expansão do setor energético (Lei no 10.847) e, em função disso, novas 
regulamentações (Lei no 10.848) para o setor foram elaboradas de modo a envolver a EPE nos investimentos em pesquisa e desenvolvimento. Assim, a lei prevê uma forma de alocação de recursos para $\mathrm{P} \& \mathrm{D}$, que para as geradoras e transmissoras se divide em:

> 40\% dos recursos: Fundo Nacional de Desenvolvimento Científico e Tecnológico (FNDCT). Os recursos são utilizados através do CT-Energ (Fundo setorial destinado ao financiamento de programas e projetos na área de energia), administrado pela Financiadora de Estudos e Projetos (Finep, empresa pública vinculada ao MCT);

v 40\% dos recursos: projetos de P\&D regulamentados pela Aneel;

จ 20\% dos recursos: EPE (Empresa de Pesquisa Energética).

Para as distribuidoras, $1 \%$ da ROL é ligeiramente diferente:

จ $30 \%$ no FNDCT;

จ 30\% "P\&D Aneel" (projetos próprios regulamentados pela Aneel);

จ $15 \% \mathrm{EPE}$

、 $25 \%$ nos programas de eficiência energética.

\section{Impactos da política de inovação}

A percepção dos entrevistados é que as empresas têm procurado se enquadrar nas determinações legais e que muitos resultados positivos das atividades de inovação estão sendo obtidos e o papel desempenhado pela Aneel tem sido relevante para isso, ainda que existam algumas restrições. Segundo as entrevistas, existe um empenho da Aneel para lidar com certos problemas burocráticos e de falta de capacitação para avaliação dos projetos. Na seleção dos projetos que compõem os programas das concessionárias, por exemplo, foi revelado que o órgão tem se portado de forma imparcial.

Outro aspecto positivo levantado pelos entrevistados foi o fato da Aneel possuir sistemas rígidos para mensurar resultados, em particular dos projetos envolvendo eficiência energética. Para cada projeto é realizado um método de mensuração de eficiência, a fim de comprovar se os objetivos do programa estão sendo alcançados. Também ocorre uma fiscalização da Aneel ao fim de cada ciclo para verificar o andamento dos projetos e a existência de irregularidades. 
Foi revelado durante as entrevistas que as empresas têm uma preocupação em comum, ou seja, tornar os resultados obtidos com os programas mais visíveis à sociedade. As empresas entendem que a visibilidade dos projetos tecnológicos é satisfatória em nível de funcionários e de parceiros, mas não em nível da sociedade como um todo. Por exemplo: algumas concessionárias possuem revistas internas como forma de disponibilizar os projetos e avanços tecnológicos realizados. Elas também realizam seminários ao término de cada ciclo, quando são convidados a Aneel, os centros de inovação, as universidades e outros órgãos do setor, bem como as demais concessionárias de energia elétrica. Entretanto, as ações desenvolvidas pelas empresas foram relatadas como não sendo de conhecimento da sociedade e o entendimento das empresas é de que esse panorama precisa mudar. As entrevistas permitiram observar que apesar da preocupação comum com a comunicação à sociedade, os esforços de comunicação (interno e externo) foram mais evidentes nas empresas cujo controle tinha participação de capital estatal nacional ou era majoritariamente privado estrangeiro. As empresas cujo controle era majoritariamente privado nacional demonstraram ser mais tímidas naquelas ações e isso foi confirmado pelos outros informantes (centros de inovação, universidades e Aneel).

As entrevistas também revelaram que em empresas com controle de capital privado nacional, as iniciativas para estimular o estabelecimento de convênios com os centros de inovação eram mais limitadas. Por exemplo: não foi incomum encontrar nas empresas de controle de capital privado estrangeiro a disponibilização, na internet, dos temas dos projetos de interesse. Dessa forma, elas ofereciam um canal que ligava diretamente o centro executor à área de interesse dentro da empresa. Além disso, segundo os entrevistados dessas empresas, esse canal visava aprimorar as propostas que seriam enviadas pelos centros de inovação e universidades. Assim, seria possível alinhar as propostas dos centros de inovação e das universidades com a realidade das concessionárias. Através desse canal de comunicação, poderiam ser incluídas ideias externas relacionadas aos temas de interesse da concessionária e também poderiam ser incluídas propostas a temas de P\&D para a concessionária. Segundo as empresas, as ideias propostas eram encaminhadas à área de interesse para apreciação e verificação, pelos gerentes de áreas e/ou comitês, do enquadramento do projeto na definição de P\&D da Aneel.

Para maior integração entre a oferta e a demanda, os entrevistados revelaram que são realizados workshops com os centros de inovação e com as universidades, em que estes têm a oportunidade de divulgar suas realizações na área e indicar suas linhas de pesquisa. Também são observados os resultados obtidos através do congresso bienal brasileiro promovido pela Aneel 
(Citenel), que tem por objetivo divulgar os resultados obtidos nos programas de pesquisa, desenvolvimento e inovação tecnológica. Os entrevistados das empresas de energia elétrica acreditam que os programas são hoje peças fundamentais no desenvolvimento de centros de pesquisa em todo o país. Existe a capacitação de indivíduos, com formação de mestres e doutores, além da geração de empregos e patentes. As concessionárias declararam buscar beneficiar o setor acadêmico com seus projetos, mas estes devem visar resultados que atendam às necessidades reais das empresas.

As entrevistas revelaram que existe um processo de aprendizagem envolvendo a concessionária, a Aneel e os prestadores de serviço de inovação (centros de inovação e universidades). Segundo os entrevistados, no início, ocorreram alguns percalços nos relacionamentos, como a falta de compromisso com os contratos estabelecidos. Todavia, isso foi relatado como mais crítico no relacionamento com as universidades do que com os centros de inovação, os quais demonstraram maior comprometimento com os resultados, segundo as empresas de energia elétrica entrevistadas. De toda a forma, os relacionamentos vêm se fortalecendo e a confiança na organização que vai dar suporte às atividades de inovação tem um grande peso na avaliação de qual organização contratar.

As entrevistas também permitiram observar que algumas concessionárias buscam criar núcleos regionais de pesquisa e desenvolvimento, que recebem auxílio para qualificação de pessoas e infraestrutura. Algumas concessionárias priorizam projetos com base na possibilidade de capacitação de funcionários. Caso um projeto ofereça a possibilidade de curso de pós-graduação para algum funcionário, ele ganha um peso mais elevado nesse critério. A capacitação interna dos funcionários foi mencionada como muito importante pelos entrevistados por elevar o comprometimento dos envolvidos com os projetos, além de garantir a gestão do conhecimento. Tais preocupações foram mais notáveis nas empresas em que o governo ainda tinha algum tipo de participação e/ou naquelas em que o controle de capital privado era estrangeiro. Isso, de fato, foi confirmado pela universidade e pelos centros de inovação entrevistados.

Também foi observado que as políticas de inovação contribuíram para a evolução da capacidade de gestão da inovação das concessionárias. Algumas, por exemplo, já possuem escritórios de patentes, especialmente aquelas em que há a presença estatal no controle de capital ou quando o controle é majoritariamente privado estrangeiro. As entrevistas revelaram que muitas das patentes são resultantes dos programas de P\&D decorrentes da política de inovação para o setor. Nessas mesmas empresas que possuem maior preocu- 
pação com propriedade industrial, também foi identificado que o escritório de patentes não trabalha de maneira isolada, pois as invenções que irão servir de base aos pedidos de patente são selecionadas em conjunto com os gestores.

\section{Entraves à inovação}

Todas as concessionárias entrevistadas reclamaram dos atrasos da Aneel na aprovação dos programas. Cortes no orçamento da agência dificultam a avaliação dos projetos nos prazos estipulados, uma vez que os avaliadores têm de ser especialistas. Em 2005, por exemplo, foi concluído o ciclo 2003/2004 de algumas concessionárias, ou seja, o ciclo 2004/2005 nem sequer tinha sido iniciado quando as entrevistas foram conduzidas. Dessa forma, o planejamento orçamentário da empresa fica comprometido, já que existe capital ocioso (que deveria estar sendo empregado com os projetos do ciclo atual). Assim, há uma dificuldade para selecionar os projetos do próximo ciclo, já que existem projetos plurianuais. $\mathrm{O}$ atraso também acarreta problemas aos institutos executores dos projetos, que têm de esperar o aval da Aneel para definir os grupos de trabalho.

De acordo com os entrevistados, havia um convênio com o CNPq (Conselho Nacional de Desenvolvimento Científico e Tecnológico) para fornecer profissionais com conhecimento para julgar os projetos, mas o convênio não foi renovado. No entanto, a Aneel utilizou, em 2005, uma nova sistemática de avaliação com o intuito de agilizar o processo. As concessionárias, junto com os centros de $\mathrm{P} \& \mathrm{D}$, têm de apresentar os projetos a professores qualificados em uma reunião, em que ocorre a defesa e aprovação desses projetos imediatamente. A ideia foi apontada por alguns entrevistados como uma boa alternativa, caso esse tipo de evento seja bem organizado e conte com a preparação prévia dos professores.

Outro entrave identificado foi o difícil acesso aos recursos do FNDCT (Fundo Nacional de Desenvolvimento Científico e Tecnológico). O FNDCT recebe recursos que são utilizados pelo CTnerg (fundo setorial que contempla o setor de energia), gerenciado por outro órgão do governo, a Financiadora de Estudos e Projetos (Finep). Os recursos contidos nesse fundo, segundo as entrevistas, são de difícil acesso. Os entrevistados argumentaram que a excessiva burocracia gera um longo e demorado processo que desestimula a utilização dessa parcela dos recursos.

O entendimento sobre o conceito de P\&D também foi apontado como outro problema para a execução dos projetos. Existe uma grande quantidade 
de projetos que não passa da fase de pré-seleção, pois as empresas sugerem projetos que não se enquadram no conceito de $\mathrm{P} \& \mathrm{D}$ adotado pelo governo. De acordo com os entrevistados, as empresas buscam realizar pesquisas de caráter aplicado, mas muitas vezes o conteúdo tecnológico do projeto não satisfaz a Aneel. Foi revelado que a Abradee (Associação Brasileira de Distribuidoras de Energia Elétrica) tem contribuído com o processo de adaptação das concessionárias aos programas de $\mathrm{P} \& \mathrm{D}$. No entanto, não se observa um envolvimento direto por parte do Operador Nacional do Sistema Elétrico (ONS) e por parte da Empresa de Pesquisa Energética (EPE) no processo.

A instabilidade do setor foi citada por algumas concessionárias como outro entrave à inovação. Ocorreram muitas mudanças nas leis do setor, assim como mudanças na gestão dos órgãos reguladores decorrentes de questões políticas, que são percebidas como uma fonte de risco aos projetos. De acordo com a Lei no 9.991/2000, a partir de 2006, o percentual dos recursos destinados aos projetos de $\mathrm{P} \& \mathrm{D}$ geridos pelas concessionárias aumentou em detrimento ao percentual empregado em programas de eficiência energética. Uma entrevista apontou que a desverticalização trouxe indefinição sobre qual receita operacional líquida deveria ser empregada para compor os recursos dos programas de P\&D.

Algumas empresas, cuja presença governamental no controle é maior, indicaram ser este um fator que prejudica o andamento de alguns projetos. Em tais empresas, as diretorias são geralmente indicadas pelo governo e com a troca de gestão de um governo a outro há uma demora na criação da assessoria responsável pelos programas, assim como na definição dos integrantes da área jurídica da própria empresa, o que atrasa o processo.

As entrevistas revelaram que, independentemente da participação governamental no controle da empresa, a gestão dos programas de P\&D também precisa ser melhorada. Os entrevistados reconheceram que é fundamental que as empresas tenham uma metodologia de acompanhamento de projetos. Muitos dos problemas existentes hoje, que resultam em atrasos no cronograma dos projetos e mudanças de orçamento, ocorrem, segundo os próprios entrevistados, devido a problemas de gestão dos programas. Alguns entrevistados sugeriram que a Aneel deveria exigir que a gerência dos projetos fosse realizada por indivíduos mais alinhados a esse perfil metodológico, pois, muitas vezes, os pesquisadores detêm o conhecimento técnico necessário ao desenvolvimento dos projetos, porém não têm capacidade de gestão. Também foi apontado como um dos grandes desafios das empresas a redundância de projetos. A falta de um banco de dados prejudica a boa avaliação dos projetos, o que torna difícil evitar a duplicação de esforços. 
As entrevistas também indicaram que os centros de P\&D das universidades propõem, com certa frequência, projetos que são economicamente inviáveis. Um dos entrevistados reportou que muitos projetos de telemedição são oferecidos, apesar do custo para a execução ser proibitivo, não remunerando o investimento. Da mesma forma, outros entrevistados enfatizaram que não compensa implementar determinadas tecnologias em algumas áreas de baixa renda, onde o consumo de energia é pequeno. Para contornar esse problema, uma concessionária revelou que os centros de P\&D que oferecem propostas têm de especificar o produto final, o custo e como o investimento vai gerar retornos à concessionária, de forma a compensar o orçamento.

Outro ponto de desgaste ocorre na cooperação com os centros de P\&D que estão com crescente interesse pelos direitos de propriedade da invenção resultante do projeto. De acordo com as entrevistas, as empresas buscam realizar acordos com os centros de $\mathrm{P} \& \mathrm{D}$ que não formalizam exigências quanto à detenção das patentes. Porém, isso não é o mais comum e convênios acabam contemplando a partilha dos direitos de propriedade sobre os resultados do projeto.

\section{Discussões e conclusões}

Esta pesquisa permitiu identificar como políticas públicas de inovação afetam o comportamento das empresas. Com base em estudos de casos de dois setores industriais foram identificadas algumas semelhanças e diferenças na forma como as empresas têm respondido às políticas de inovação. Os casos estudados sugerem um efeito positivo das políticas adotadas, sendo que a extensão do impacto destas sobre as empresas parece estar relacionada a quatro aspectos: 1 . ao ambiente institucional; 2 . aos incentivos governamentais para investimentos em P\&D; 3. à demanda por investimentos em centros de $\mathrm{P} \& \mathrm{D}$ externos às empresas; e 4. às competências tecnológicas locais.

Os casos confirmam que o "ambiente institucional" exerce um papel fundamental na implementação e na criação de um ambiente para inovação. Tanto a Aneel, no caso da energia elétrica, como a Suframa, no caso de bens de informática em Manaus, contribuem significativamente para aquele ambiente. Ambas têm exercido um papel de liderança na formulação e implementação das políticas de inovação nas indústrias estudadas. Os estudos de casos confirmaram que existem algumas diferenças no escopo de atuação das duas organizações. Apesar de ambas terem uma preocupação com a criação de competências tecnológicas, a atuação da Aneel é um pouco mais limitada. 
Nesse aspecto de geração de conhecimento, a Aneel está concentrada na indução de atividades de P\&D, enquanto a Suframa tem atuado tanto na promoção de atividades de P\&D quanto na qualificação de mão de obra através do apoio à oferta de cursos de pós-graduação na região.

A obrigatoriedade das empresas do setor elétrico de investirem em P\&D em determinadas partes do país mais carentes de competências tecnológicas não foi suficiente para a Aneel atuar de forma mais direta na formação de recursos humanos naquelas regiões. É possível que objetivos específicos de cada organização sejam a provável causa dessa diferença. Além disso, a dimensão (nacional ou regional) de atuação de cada organização pode afetar o escopo de suas atividades. Por exemplo: por ter seu nível de atuação nacional, a Aneel entende que determinados aspectos para o fortalecimento do ambiente institucional não fazem parte do seu escopo de atuação, tendo em vista que existem outras organizações habilitadas para isso. No entanto, o fato da Suframa estar tendo uma atuação mais direta na execução de funções que, a princípio, estão fora de suas atribuições, não significa que a Aneel deva fazer o mesmo. Torna-se relevante uma reflexão sobre como as políticas públicas devem ser desenhadas, de forma a criar um ambiente institucional favorável à inovação, evitando sobreposição de papéis dos agentes envolvidos ou fazendo-os exercer seus papéis de facto.

Apesar da Suframa atuar mais diretamente na promoção da qualificação de mão de obra do que a Aneel, em ambas as indústrias estudadas foi possível observar que as políticas de inovação têm contribuído para o "fortalecimento das competências tecnológicas locais". A ausência de recursos humanos devidamente qualificados em Manaus e a obrigatoriedade de investir em P\&D na região aumentaram o interesse das empresas pela qualificação da mão de obra local. No caso das empresas de energia elétrica, mesmo não tendo a obrigatoriedade de investirem localmente e tendo mais flexibilidade para utilizarem as competências geradas em outras partes do país, o mesmo fenômeno foi constatado, ou seja, o interesse no fortalecimento das competências tecnológicas locais. Embora possa ser argumentado que este último não é decorrente de uma ação política direta, as entrevistas sugerem que o interesse das empresas pela formação de competências tecnológicas locais ocorreu, principalmente, devido aos incentivos para investirem em P\&D.

$\mathrm{O}$ interesse das empresas engajadas em inovação em desenvolver competências localmente sugere que a proximidade é um elemento importante para o processo de aprendizagem e que uma base de competências locais se faz necessária para facilitar a internalização do conhecimento. Dessa forma, merece reflexão até que ponto as políticas de inovação devem determinar a 
alocação dos recursos de P\&D das empresas. Conforme observado em Manaus, a obrigatoriedade das empresas investirem em P\&D externamente fez com que algumas empresas criassem centros de inovação para desenvolverem trabalhos exclusivos para elas (pelo menos num primeiro momento). Todavia, de acordo com as entrevistas, o propósito da obrigatoriedade de investir externamente era distribuir os recursos entre as organizações locais para fortalecê-las e, também, incentivar a criação de novos centros privados de inovação. No entanto, não se esperava que algumas empresas viessem, elas próprias, a criar novos centros privados de inovação, de forma a concentrar neles seus recursos de P\&D.

Ainda que a política de inovação tenha sido formulada para fortalecer as competências locais, as evidências do setor de energia elétrica sugerem que essa seria uma decorrência natural do processo de aprendizagem à medida que as empresas se esforçam para inovar. Parece mais relevante, conforme proposto pela abordagem do sistema nacional de inovação (Freeman, 1995), enfocar no desenvolvimento de mecanismos de incentivo às interações entre os vários agentes de maneira mais eficaz do que enfocar na forma como os investimentos devam ser distribuídos.

Pode-se questionar se as empresas de bens de informática de Manaus possuem "incentivos para investir em centros de P\&D externos", já que existem características distintas do setor de energia elétrica, tais como número de empresas, mercado e rivalidade. A abordagem dos sistemas de inovação (Edquist e Johnson, 1997) e os trabalhos empíricos dela decorrentes (Asheim e Coenen, 2004) têm reforçado o papel da interação no processo de acúmulo de competências tecnológicas. Apesar de interação não significar investimentos em P\&D externamente, a exigência legal de se investir externamente poderia ser, em si, o principal motivo para tais investimentos. Todavia, os trabalhos empíricos (Porter, 1990) sugerem a necessidade de alguns elementos essenciais para que a região de origem da empresa contribua para o seu fortalecimento competitivo, entre os quais o nível de conhecimento da mão de obra local. A baixa disponibilidade de recursos humanos qualificados para atividades de inovação tecnológica em Manaus poderia ser suprida por outras regiões do país, como de fato vem ocorrendo, mas isso implica maiores custos. Portanto, seria esperado o interesse das empresas em recrutar mão de obra local qualificada e, na sua inexistência, em contribuir para a formação desta. Dada a natureza das atividades e a necessidade de formação de recursos humanos, também seria esperado que as empresas se aproximassem das universidades para desenvolverem projetos em conjunto. Dessa forma, parece que parte dos 
recursos destinados para P\&D seria naturalmente alocado em centros de pesquisa externos às empresas.

Nas entrevistas foi constatada a insatisfação dos centros de $\mathrm{P} \& \mathrm{D}$ privados (centros de inovação) com a forma como as políticas de inovação induzem à distribuição dos recursos em P\&D. Porém, o que se percebeu das empresas é que o papel desempenhado por aqueles centros é distinto das universidades e que na ausência de competências internas ou por outras condições de mercado, as empresas buscariam desenvolver atividades com eles. Nesse ponto cabe uma reflexão sobre o processo de surgimento de organizações com esse perfil. Conforme observado por Davis (2005), a noção de que o conhecimento é vital na nova economia tem contribuído para o surgimento de organizações cujo modelo de negócios é, essencialmente, baseado na geração e comercialização de novos conhecimentos. A autora descreve vários casos sobre a origem desses centros de inovação e pode-se observar que o surgimento destes foi decorrente de condições de mercado ao invés de ações diretas de políticas de inovação. A tentativa de acelerar o processo de desenvolvimento de laboratórios de P\&D, sem criar condições mais favoráveis para a sua atuação, pode levar à alocação ineficiente de recursos, como constatado por Ronstadt (1984) e como a que ocorreu na própria indústria brasileira de polímeros (Hemais, Barros e Rosa, 2003).

Importante destacar ainda que, além das competências tecnológicas locais serem limitadas, a fragilidade do arcabouço institucional para promover a inovação se reflete também na própria implementação das políticas de inovação. As dificuldades para operacionalizar adequadamente as análises dos projetos em ambas as indústrias retrata a incapacidade do governo em responder com mais agilidade às ações empresariais, gerando ainda mais incerteza em um ambiente que já intrinsecamente possui essa característica. Isso faz com que as políticas de inovação pouco contribuam para promover inovação nas empresas privadas de capital nacional, em que provavelmente reside o principal alvo de tais políticas. Ao analisar, com base nas entrevistas, o comportamento dessas empresas de capital privado nacional, se conclui que o impacto das políticas de inovação nas empresas privadas é menor do que nas empresas de controle estatal ou de capital privado estrangeiro. O setor de bens de informática, por exemplo, que não opera dentro de um aparato regulatório rígido, tem presenciado empresas de capital estrangeiro buscando utilizar de forma produtiva os recursos que devem alocar para P\&D. Entretanto, esse comportamento nas empresas de capital privado nacional pareceu apenas marginal.

Sendo assim, apesar de maior concorrência no setor de bens de informática e da tentativa governamental de estimular as empresas a ganharem 
competitividade através da inovação, o incentivo ainda não foi o suficiente para muitas empresas, especialmente as de capital privado nacional. Isso nos leva a concluir que as políticas de inovação vigentes têm tido um alcance limitado; o que reforça a ideia de que outras partes relevantes para o processo de inovação precisam estar bem integradas para que as empresas sejam, de fato, estimuladas a inovar (Metcalfe, 1995). Da mesma forma, os resultados confirmam que o enfoque das políticas de inovação no lado da oferta pode não ser suficiente para criar incentivos para as empresas investirem em P\&D (Mowery, 1995). Cabe, portanto, ao governo ter uma visão mais abrangente de tais políticas se o propósito é estimular a inovação no país.

Assim, este estudo nos permitiu observar que, em linhas gerais, os efeitos das políticas públicas para a inovação no Brasil têm sido positivos, mas de limitado alcance. De fato, a inovação parece estar mais presente hoje nos setores e o desenvolvimento de competências tecnológicas parece ser expressivo quando comparado com o que havia antes da implementação de tais políticas. No entanto, para que as políticas de inovação tenham maior eficácia, uma perspectiva mais abrangente se faz necessária. $\mathrm{O}$ limitado interesse por inovação das empresas de capital privado nacional sugere que as políticas de inovação não podem englobar apenas ações voltadas para o lado da oferta, nem podem ser dissociadas de políticas voltadas para o fortalecimento do ambiente institucional.

\section{Referências}

ARIFFIN, N.; FIGUEIREDO, P. N. Internacionalização de competências tecnológicas: implicações para estratégias governamentais e empresariais de inovação e competitividade da indústria eletrônica no Brasil. Rio de Janeiro: Editora FGV, 2003.

ASHEIM, B. T.; COENEN, L. The role of regional innovation systems in a globalising economy: comparing knowledge bases and institutional frameworks of nordic clusters. In: DRUID SUMMER CONFERENCE 2004. Proceedings... Copenhagen. Disponível em: <www.druid.dk>. Acesso em: 10 jun. 2005.

BRUYNE, P. de; HERMAN, J.; SCHOTHEETE, M. de. Dinâmica da pesquisa em ciências sociais: os polos da prática metodológica. Rio de Janeiro: Francisco Alves, 1982.

CANTWELL, J. The globalisation of technology: what remains of the product cycle? Cambridge Journal of Economics, v. 19, n. 1, p. 155-174, 1995. 
CARNEIRO, R. Estado, mercado e o desenvolvimento do setor elétrico brasileiro. Tese (Doutorado em Ciências Humanas) - Sociologia e Política, Universidade Federal de Minas Gerais, Belo Horizonte, 2000.

CASSIOLATO, J. E.; LASTRES, H. M. M. Local systems of innovation in Mercosur countries. Industry and Innovation, v. 7, n. 1, p. 33-53, 2000.

COOKE, P. Regional innovation systems, clusters, and the knowledge economy. Industrial and Corporate Change, v. 10, n. 4, p. 945-974, 2001.

DAVIS, L. Licensing strategies of the new intellectual property vendors. In: DRUID SUMMER CONFERENCE 2005. Proceedings... Copenhagen. Disponível em: <www. druid.dk>. Acesso em: 10 ago. 2005.

DUNNING, J. H. Multinational enterprises and globalization of innovatory capacity. Research Policy, v. 23, p. 67-88, 1994.

EDQUIST, C. Systems of innovation approaches - their emergence and characteristics. In: EDQUIST, C. (Ed.). Systems of innovation: technologies, institutions and organizations. London: Pinter, 1997.

; JOHNSON, B. Institutions and organizations in systems of innovation. In: EDQUIST, C. (Ed.). Systems of innovation: technologies, institutions and organizations. London: Pinter, 1997. p. 41-63.

FREEMAN, C. The national system of innovation in historical perspective. Cambridge Journal of Economics, v. 19, n. 1, p. 5-24, 1995.

GAMMELTOFT, P. Internationalization of R\&D: trends, drivers, and managerial challenges. International Journal of Technology and Globalization, v. 2, n. 1/2, p. 177-199, 2006.

GARCIA, E. Modelo de desenvolvimento Zona Franca de Manaus: história, conquistas e desafios. Manaus: Norma Editora, 2004.

GIL, A. C. Métodos e técnicas de pesquisa social. São Paulo: Atlas, 1995.

GODOY, A. S. Pesquisa qualitativa: tipos fundamentais. Revista de Administração de Empresas, v. 35, n. 3, p. 20-29, maio/jun. 1995.

HEMAIS, C. A.; BARROS, H. M.; ROSA, E. O. R. The evolution of R\&D laboratories in the brazilian polymer industry. Latin American Business Review, v. 4, n. 1, p. $61-75,2003$.

KATZ, J. The limits of the prevailing orthodoxy: technology and education as restriction to productivity growth and international competitiveness in Latin America. In: DRUID SUMMER CONFERENCE 2004. Proceedings... Copenhagen. Disponível em: <www.druid.dk>. Acesso em: 10 ago. 2005. 
LUNDVALL, B. National innovation systems - analytical concept and development tool. In: DRUID SUMMER CONFERENCE 2005. Proceedings... Copenhagen. Disponível em: <www.druid.dk>. Acesso em: 10 ago. 2005.

METCALFE, S. The economic foundations of technology policy - equilibrium and evolutionary perspectives. In: STONEMAN, P. (Ed.). Handbook of the economics of innovation and technological change. Oxford: Blackwell, 1995. p. 410-512.

MOWERY, D. The practice of technology policy. In: STONEMAN, P. (Ed.). Handbook of the economics of innovation and technological change. Oxford: Blackwell, 1995. p. 513-557.

NELSON, R. R.; WINTER, S. G. In search of useful theory of innovation. Research Policy, v. 6, n. 1, p. 36-76, 1977.

1982. . An evolutionary theory of economic change. Cambridge: Belnaps,

PATEL, P.; PAVITT, K. Large firms in the production of the world's technology: an important case of non-globalization. In: GRANSTRAND, O.; HÅKANSON, L.; SJÖLANDER, S. (Eds.). Technology management and international business - internationalization of R\&D and technology. London: Pinter, 1991. p. 53-74.

PORTER, M. E. Competitive advantage of nations. New York: Free Press, 1990.

PORTER, M. E. Locations, clusters and company strategy. In: CLARK, G. L.; FELDMAN, M. P.; GERTLER, M. S. (Eds.). The Oxford handbook of economic geography. Oxford: Oxford University Press, 2000. p. 253-274.

ROMER, P. M. Increasing returns and long-run growth. The Journal of Political Economy, v. 94, n. 5, p. 1002-1037, 1986.

. Endogenous technological change. The Journal of Political Economy, v. 98, n. 5, p. S71-S102, 1990.

RONSTADT, R. C. R\&D abroad by US multinationals. In: STOBAUGH, R.; WELLS JR., L. T. Technology crossing borders: the choice, transfer, and management of international technology flows. Boston: Harvard Business Press, 1984. p. 241-264.

SAXENIAN, A. Regional advantage: culture and competition in Silicon Valley and Route 128. Cambridge: Harvard University Press, 1994.

SANTOS JUNIOR, F. B. Investimentos de pesquisa e desenvolvimento em Manaus. Monografia (Pós-Graduação em Economia Regional) — Departamento de Economia e Análise, Universidade Federal do Amazonas, Manaus, 2004.

SCHUMPETER, J. A. Capitalism, socialism and democracy. New York: Harper and Row, 1942. 
SOLOW, R. M. Technical change and the aggregate production function. The Review of Economics and Statistics, v. 39, p. 312-320, 1957.

TEIXEIRA, F. L. C. Desenvolvimento industrial e tecnologia: revisão da literatura e uma proposta de abordagem. Cadernos EBAPE.BR, 2005. Edição especial. Disponível em: <www.ebape.fgv.br/cadernosebape>. Acesso em: 25 ago. 2005.

VON ZEDTWITZ, M.; GASSMANN, O. Market versus technology drive in R\&D internationalization: four different patterns of managing research and development. Research Policy, v. 31, p. 569-588, 2002.

YIN, R. K. Case study research: design and methods. London: Sage, 1994.

YOUNG, A. A. Increasing returns and economic progress. The Economic Journal, v. 38, n. 152, p. 527-542, 1928. 